\title{
Des bibliothèques pour un meilleur développement culturel au Québec
}

\author{
Mémoire soumis à la Commission de la culture
}

Cultural Development of Québec and Its Libraries

A Report Presented to the Commission de la culture

Bibliotecas para un mejor desarrollo cultural en Quebec

Informe sometido a la Comisión de la cultura

\author{
Association pour l'avancement des sciences et des techniques de la \\ documentation (ASTED)
}

Volume 37, numéro 4, octobre-décembre 1991

URI : https://id.erudit.org/iderudit/1028544ar

DOI : https://doi.org/10.7202/1028544ar

\section{Aller au sommaire du numéro}

\section{Éditeur(s)}

Association pour l'avancement des sciences et des techniques de la documentation (ASTED)

\section{ISSN}

0315-2340 (imprimé)

2291-8949 (numérique)

\section{Découvrir la revue}

Citer cet article

Association pour l'avancement des sciences et des techniques de la documentation (ASTED) (1991). Des bibliothèques pour un meilleur développement culturel au Québec : mémoire soumis à la Commission de la culture. Documentation et bibliothèques, 37(4), 133-135.

https://doi.org/10.7202/1028544ar
Résumé de l'article

Le Comité de rédaction de Documentation et bibliothèques publie le mémoire que le Conseil d'administration de l'ASTED a préparé et a fait parvenir à la Commission parlementaire sur la culture qui étudie les recommandations du Rapport Arpin. Il n'est habituel que la revue publie les " mémoires " préparés par l'Association. Mais il a semblé aux membres du Comité de rédaction que le sujet traité dans ce document revêtait une telle acuité qu'il était essentiel de le porter à la connaissance des membres de l'Association et des lecteurs de la revue.
Tous droits réservés $@$ Association pour l'avancement des sciences et des techniques de la documentation (ASTED), 1991
Ce document est protégé par la loi sur le droit d'auteur. L'utilisation des services d'Érudit (y compris la reproduction) est assujettie à sa politique d'utilisation que vous pouvez consulter en ligne.

https://apropos.erudit.org/fr/usagers/politique-dutilisation/ 


\title{
Des bibliothèques pour un meilleur développement culturel au Québec
}

\author{
Mémoire soumis à la Commission de la culture*
}

par I'Association pour l'avancement des sciences et des techniques de la documentation (ASTED)

Le Comité de rédaction de Documentation et bibliothèques publie le mémoire que le Conseil d'administration de l'ASTED a préparé et a fait parvenir à la Commission parlementaire sur la culture qui étudie les recommandations du Rapport Arpin. II n'est habituel que la revue publie les "mémoires" préparés par l'Association. Mais il a semblé aux membres du Comité de rédaction que le sujet traité dans ce document revêtait une telle acuité qu'il était essentiel de le porter à la connaissance des membres de l'Association et des lecteurs de la revue.

\section{Cultural Development of Québec and Its Libraries: A Report Presented to the Commission de la culture by the Association pour l'avancement des sciences et des techniques de la documentation (ASTED)}

The editorial board of Documentation et bibliothèques presents the report prepared by the board of directors of ASTED and presented to the Commission parlementaire sur la culture, which is currently studying the recommendations of the Arpin Report. Although it usually does not publish the Association's reports, the members of the editorial board believe the subject to be timely and that it should be brought to the attention of the members and other readers.

\begin{abstract}
Bibliotecas para un mejor desarrollo cultural en Québec. Informe sometido a la Comisión de la cultura por la Association pour l'avancement des sciences et des techniques de la documentation (ASTED)
\end{abstract}

El Comité de redacción de Documentation et bibliothèques publica el informe que el Consejo de Administración de la ASTED preparó y envió a la Comisión parlamentaria sobre la cultura que estudia las recomandaciones del Rapport Arpin. No es habitual que la revista publique los informes preparados por la Asociación. Pero ha parecido a los miembros del Comité de redacción que el tema tratado en este documento presentaba un tal interés que era esencial llevarlo al conocimiento de los miembros de la Asociación y a los lectores de la revista.

\section{PRÉAMBULE}

La volonté de la ministre des Affaires culturelles, madame Liza FrullaHébert, de situer la culture au coeur des préoccupations gouvernementales et, de ce fait, de constituer un groupe de travail mandaté pour jeter les bases d'une réflexion sérieuse pour l'édification d'une politique des arts et de la culture, est une démarche salutaire et bienvenue. $\mathrm{Ce}$ processus devrait amener tous les intervenants du milieu culturel à participer à l'élaboration d'une véritable politique culturelle.

Toutefois le Groupe-conseil, sous la présidence de monsieur Roland Arpin, a suscité des déceptions dans les milieux documentaires du Québec. En effet, nous déplorons vivement qu'aucun représentant du domaine des bibliothèques et des archives n'ait été invité à y participer. Ce représentant aurait agi comme personne-ressource lors des délibérations du Groupeconseil. Sa contribution aurait permis une meilleure définition de la place des bibliothèques dans le cadre d'une politique de la culture et des arts au Québec. Aussi, I'ASTED ne peut que constater l'absence de l'argumentation et de la place accordée aux bibliothèques dans le rapport Une Politique de la culture et des arts ${ }^{1}$.

À notre avis, les traits distinctifs du Québec seront mieux caractérisés, préservés et promus dans une politique culturelle profitant à l'épanouissement de la société québécoise que par tout autre moyen législatif. Dans un tel contexte, la bibliothèque publique doit donc occuper une place prépondérante, car sa nature et ses fonctions lui permettent de favoriser l'épanouissement des connaissances, de contribuer au rayonnement et à la diffusion du savoir et de faciliter la transmission des valeurs culturelles utiles à une compréhension de notre société.
Les bibliothèques publiques du Québec permettent aux contribuables québécois de réaliser une ÉCONOMIE FORT SUBSTANTIELLE estimée à 439128412 \$ pour 1989. En effet, si nous donnons la valeur moyenne de 19,50 \$ par livre acheté par les bibliothèques publiques québécoises en 1989 et si nous multiplions ce montant par le nombre total de prêts, nous arrivons à une dépense de 546774730 \$ que les abonnés auraient eu à débourser de leurs poches pour jouir d'un tel avantage. Si nous soustrayons les dépenses nettes de ce montant, incluant les 22407813 \$ de subventions, soit $107646318 \$$, les Québécois ont ainsi économisé $439128412 \$$, soit $67,14 \$$ par citoyen ou 292,98\$ par abonné.

\footnotetext{
* Ce mémoire fut soumis en septembre 1991.

1. Une Politique de la culture et des arts. Proposition présentée à madame Liza FrullaHébert, ministre des Affaires culturelles du Québec, $2^{\circ}$ éd. [Québec] 1991, 328 p.
} 
La bibliothèque publique est l'institution culturelle par excellence et la plus accessible, voire démocratique, à la population. La bibliothèque par la variété de ses collections peut donc répondre au besoin de tous les citoyens quel que soit leur âge ou statut social.

Soulignons que la bibliothèque publique crée, par sa présence et son rayonnement, une demande pour les autres biens culturels.

Cette demande se traduit par la fréquentation accrue à d'autres formes d'art ou activités culturelles. Le constant souci d'excellence du rôle joué par la bibliothèque et sa vocation de lieu d'information contribuent à l'amélioration de notre qualité de vie.

\section{POSITION DE L'ASTED}

L'Association pour l'avancement des sciences et des techniques de la documentation (ASTED) souscrit d'emblée aux trois principes fondamentaux qui ont guidé la réflexion du Groupe-conseil et par la suite orienté la rédaction du Rapport ${ }^{2}$ :

- développer le domaine des arts et de la culture ;

- favoriser l'accès à la vie culturelle ;

- accroître l'efficacité du gouvernement et de ses partenaires dans la gestion de la mission culturelle.

À ceux-ci, il aurait fallu rajouter un principe essentiel à la culture qui confirme l'importance de l'écrit, soit l'information et la documentation.

La connaissance de l'écrit est une composante nécessaire à toute activité culturelle. On ne peut concevoir une politique culturelle sans promouvoir un plan d'action concernant l'alphabétisation.

\section{Développer le domaine des arts et de la culture}

Bien que nous reconnaissions l'importance de la création et du créateur dans le développement de la vie culturelle, I'ASTED ne saurait se satisfaire de ces seuls considérants pour développer le domaine des arts et de la culture.

L'ASTED considère toujours valable l'affirmation contenue dans son mémoire présenté à la Commission d'étude sur les bibliothèques publiques du Québec ${ }^{3}$ (Rapport Sauvageau), reconnaissant à celles-ci le mérite d'avoir bien rempli les trois missions d'éducation, de loisir et de culture; mais il s'agit plutôt de les inscrire dans une perspective de développement en matière d'information culturelle, scientifique, technique et économique:

Lorsque nous faisons référence à la bibliothèque publique du Québec, c'est moins à une institution en particulier à laquelle nous pensons qu'à un ensemble d'institutions, de services, de moyens techniques, financiers, administratifs et politiques permettant aux bibliothèques publiques de fonctionner comme une seule et dont les limites sont désormais à l'échelle du Québec et même davantage. Ce concept n'est pas une abstraction: il est la somme des expériences tentées et réussies ailleurs. Le retard du Québec n'est pas un handicap irrémédiable s'il lui permet de faire l'économie d'étapes intermédiaires et d'entrer de plein pied dans la phase contemporaine du développement des bibliothèques publiques 4 .

\section{Absence de législation}

Le milieu documentaire québécois est toujours dans l'attente d'une législation sur les bibliothèques publiques. La loi actuelle, datant de 1959, que le Rapport Sauvageau décrétait en 1987 comme inadéquate, ne répond plus de toute évidence aux besoins nés de l'évolution considérable des 30 dernières années des bibliothèques publiques.

\section{L'ASTED recommande que le Gou- vernement du Québec établisse la base juridique propice au dévelop- pement des bibliothèques publi- ques et en fixe les principes direc- teurs en accord avec ses principaux partenaires.}

\section{Favoriser l'accès à la vie culturelle}

La lecture occupe une position des plus privilégiées dans les pratiques culturelles des Québécois. Au chapitre de la fréquentation des établissements culturels, les bibliothèques occupent une position de très loin supérieure à toutes autres institutions réunies sur le plan statistique ${ }^{5}$.
À cet égard, I'ASTED considère que les efforts consentis aux bibliothèques publiques depuis ces dernières années ne sont pas une fin en soi mais plutôt une étape nous amenant à la consolidation d'un réseau mieux structuré et mieux organisé.

L'ASTED a toujours cherché à favoriser la lecture à travers des campagnes de promotion, la tenue de colloques, la production d'outils de travail (tel Animer la lecture), la mise en place de comités de travail, etc. Cette préoccupation constante pour la promotion de la lecture traduit bien l'importance de cette pratique pour notre organisme et de la fonction que doit jouer la lecture dans la culture d'un peuple.

Nous saluons le courage du Rapport qui, avec beaucoup de justesse, n'hésite pas à relier la situation de la lecture aux ressources dont peuvent disposer les bibliothèques.

De toute évidence, la situation de la lecture chez les jeunes et celle d'une certaine pauvreté de nos bibliothèques publiques, malgré des efforts importants déjà consentis et une récente relance, sont des questions qui devraient faire partie des dossiers prioritaires de la concertation entre le ministère des Affaires culturelles et le ministère de l'Éducation6.

L'ASTED recommande que le ministère des Affaires culturelles mette en place, avec la collaboration de ses partenaires concernés par la problématique de la lecture, une politique de lecture publique adaptée à la réalité québécoise.

2. Pour fins de compréhension du texte, il est convenu d'employer Rapport pour désigner le document Une Politique de la culture et des arts.

3. Les bibliothèques publiques: une responsabilité à partager. Rapport de la Commission d'étude sur les bibliothèques publiques du Québec, Québec, 1987, 359 p.

4. Des responsabilités partagées dans une structure unifiée. Mémoire soumis à la Commission d'étude sur les bibliothèques publiques, ASTED, avril 1987, p. 8.

5. Voir le rapport du Groupe-conseil, chapitre 2, tableau 8, page 121.

Voir aussi, Etude sur le financement des arts et de la culture au Québec, Samson Bélair, Deloitte \& Touche, novembre 1990, p.50 (Tableau 3.1).

6. Une Politique de la culture et des arts..., p. 155. 


\section{Les institutions nationales}

\section{La Bibliothèque nationale du Québec}

Dans la perspective de favoriser l'accès à la vie culturelle, nous soulignons la pertinence du propos du Rapport en ce qui a trait à la Bibliothèque nationale du Québec.

Seule la Bibliothèque nationale demeure en attente d'une décision de développement et de relocalisation qui lui permettrait de jouer véritablement son rôle. Le temps semble venir de passer à l'étape de ce projet et de terminer ainsi le réseau des institutions nationales?.

L'ASTED recommande que le ministère des Affaires culturelles favorise, grâce à un soutien financier approprié et une volonté expresse, la réalisation d'un immeuble pouvant accueillir de façon adéquate la Bibliothèque nationale du Québec.

\section{Les Archives nationales du Québec}

L'ASTED désire apporter une nuance au Rapport qui laisse sous-entendre que le réseau des Archives nationales est bien consolidé. II nous est difficile de croire à une telle affirmation, alors que le Centre des Archives nationales de la région de Montréal, ville-hôte du prochain Congrès international des archives, aurait dû être relocalisé depuis longtemps.

L'ASTED recommande que le ministère des Affaires culturelles prenne une décision dans les plus brefs délais quant à la relocalisation du Centre des Archives nationales du Québec à Montréal.

\section{Le droit d'auteur}

Cette question est traitée avec une simplicité qui laisse penser que la mise en place d'une structure de perception du droit d'auteur ainsi que l'information faite auprès du public sont les solutions toutes désignées. Cette vision limitée cache une réalité beaucoup plus complexe. Car il n'est pas fait mention des exceptions en matière de droits d'auteur que le milieu documentaire réclame à juste titre et qui sont autant de moyens pouvant permettre aux utilisateurs d'accéder après coup à l'oeuvre originale. À titre d'exemple, citons la reproduction d'une copie unique d'un article de périodique pour des fins d'étude ou de recherches individuelles, ou encore la reproduction d'un ouvrage en exem- plaire unique quand il est nécessaire d'assurer la conservation de l'exemplaire original ou de remplacer un ouvrage qui n'est plus disponible sur le marché.

Accroître l'efficacité du gouvernement et de ses partenaires dans la gestion de la mission culturelle

Ce dernier volet, ambitieux à plusieurs égards, arrive à un fort mauvais moment. Les principaux partenaires de l'État en ce qui regarde les bibliothèques publiques sont les municipalités. L'ASTED est consciente des lourdes responsabilités échues aux municipalités depuis la réforme Ryan. Dans ce contexte, l'ASTED s'inquiète des conséquences possibles de certains choix qu'auront à faire les élus municipaux: la répartition de ces sommes se fera-t-elle au détriment du développement des bibliothèques publiques?

L'ASTED recommande que le ministère des Affaires culturelles établisse des normes minimales de gestion des bibliothèques afin que les municipalités soient "incitées " par des mesures précises à pourvoir leur bibliothèque de personnels qualifiés habilités à gérer et développer cette institution de façon harmonieuse.

\section{Montréal, métropole culturelle}

Le Rapport évoque un rôle prépondérant pour Montréal en ce qui regarde le développement de la culture et l'incidence du rôle sur la vie culturelle de tout le Québec. Montréal est même présentée comme "le principal creuset par lequel se forme le Québec de l'avenir " 8 . Cette affirmation très sensée cache toutefois une réalité qui fait en sorte que Montréal ne reçoit pas toute la considération financière qu'elle serait en droit d'attendre pour son réseau des bibliothèques.

Le Rapport établit des obligations pour Montréal sans indiquer les mesures ou moyens que l'État québécois doit contribuer afin de traduire de tels objectifs en réalités concrètes et en retombées directes pour la formation, l'éducation et le loisir de la population.

L'ASTED recommande que le ministère des Affaires culturelles reconnaisse la situation particulière de la Ville de Montréal en allouant des sommes nécessaires visant à garantir le développement de son réseau de bibliothèques publiques.

\section{L'ensemble régional}

Le Rapport est soucieux de situer l'importance de rendre la culture accessible en régions. L'ASTED craint cependant que l'exercice suggéré au ministère relatif à la carte de la distribution des équipements culturels se fasse au détriment des bibliothèques. Les assertions du Rapport sont inquiétantes.

II faut que le ministère des Affaires culturelles dise clairement, par exemple, quels sont les musées privés qu'il accepte de subventionner, pourquoi il fait certains choix et de quelle importance seront les subventions pour les diverses catégories de musées et de centres d'expositions. II en est de même pour les salles de spectacles et les bibliothèques 9 .

L'ASTED considère que l'une des solutions au problème du sousdéveloppement culturel en région passe par la mise en place de bibliothèques pouvant répondre à des besoins multiples et desservant les usagers en région par des activités diverses - expositions, projections de films, prêts d'oeuvres d'art, conférences, etc.

II nous apparaît plus conséquent d'investir dans une institution pouvant remplir des rôles multiples que d'allouer des subsides à la construction d'immeubles à vocation unique en région.

\section{Le financement}

L'ASTED accueillerait avec beaucoup d'intérêt une proposition favorisant le soutien des organismes culturels par le biais d'ententes triennales articulées autour de projets spécifiques ayant une incidence sur le développement des bibliothèques publiques. Cette approche favoriserait une meilleure planification et rendrait possible la réalisation de projets qui ne pourraient voir le jour autrement.

L'ASTED recommande que le ministère des Affaires culturelles puisse envisager une formule de soutien financier, sur une base de trois ans, aux bibliothèques publiques du Québec.
7. Ibid., p. 68.
8. Ibid, p. 119.
9. Ibid., p. 132. 